\title{
Standardized Assay for the Sodium Reabsorption Inhibitory Effect and Studies of Its Salivary Gland Distribution in Patients with Cystic Fibrosis
}

\author{
ANNE TAYLOR, JOSEPH W. MAYO, THOMAS F. BOAT, AND LEROY W. MATTHEWS ${ }^{(26)}$
}

Department of Pediatrics, Case Western Reserve School of Medicine, Cleveland, Ohio

\section{Extract}

The retrograde perfusion assay of Mangos for the sodium reabsorption inhibitory effect in sweat and mixed saliva from patients with cystic fibrosis (CF) was modified by (1) using the second parotid gland of the rat as a control, (2) carefully controlling the quantity of saliva perfused into the rat parotid gland so that the ratio of milliliters perfused to gram dry gland weight fell between 1.8 and 2.8 , and (3) reporting the inhibitory effect as percentage of inhibition of the rate of sodium reabsorption $\left(R_{\mathrm{Na}_{\mathrm{a}}}\right)$ in the perfused gland calculated from the difference between the $R_{\mathrm{N}}$ 's in the two glands. Using this modified assay we were able to confirm that significant differences exist in the percentage of inhibition of $\mathbf{R}_{\mathbf{N}}$ a caused by $C F$ and normal mixed saliva $(47.0 \pm 24.8$ and $18.0 \pm 8.3$, mean \pm SD). In addition, similar significant differences in the percentage of inhibition of $\mathbf{R}_{\mathrm{Na}}$ by submandibular gland secretions $(39.7 \pm 13.5$ and $16.0 \pm 11.8)$, sublingual gland secretions $(39.5 \pm 6.0$ and $19.7 \pm 14.3)$, and submucosal gland secretions $(34.0 \pm 11.7$ and $21.7 \pm 12.7)$ between $C F$ and normal subjects were observed. However, parotid gland secretions from CF subjects showed no increased inhibitory effect $(12.5 \pm 7.9$ and $12.5 \pm 6.6)$. These findings demonstrate that the sodium reabsorption inhibitory effect is produced by the secretions from some but not all salivary glands of patients with CF.

\section{Speculation}

These results indicate that the substance or substances responsible for the sodium reabsorption inhibitory effect of CF secretions is produced by cells present in submandibular, sublingual, and submucosal glands of patients with CF. Because mucus-producing cells are abundant in submandibular, sublingual, and submucosal glands, but are sparse in parotid glands (1) we suggest, as have Johansen et al. (4), that the inhibitory effect is in some way related to the mucous secretory product of the cystic fibrosis glands.

Cystic fibrosis is an inherited disease involving the exocrine glands. The most consistent finding in this disease is that of elevated concentrations of chloride and sodium in sweat (2) and secretions of the minor salivary glands (14). The pathophysiology of this alteration has not been clearly defined. Mangos et al. (12) and Mangos and McSherry (10) have shown that retrograde perfused CF sweat and saliva inhibit sodium reabsorption in the ducts of the rat parotid glands. Studies by Kaiser et al. (5) also show that sweat from CF patients causes inhibition of sodium reabsorption when it is perfused into normal human sweat gland ducts. A specific sodium reabsorption inhibitory factor $(5,10-12)$ may be the cause of the elevated sodium concentrations found in these secretions; however, such a factor has not been identified.

The sodium reabsorption inhibitory effect in rat parotid gland ducts has not been reproduced by other laboratories. Using a modification of the Mangos technique we now have been able to demonstrate a sodium reabsorption inhibitory effect in mixed saliva of patients with CF. Further work in our laboratory has shown the effect to be caused by some, but not all of the specific salivary gland secretions of CF patients. It is hoped that the detailed methodology reported here will lead to reproducible results in other laboratories and will serve as a useful tool in the isolation and identification of the factor responsible for this effect.

\section{METHODS}

\section{PATIENTS AND CONTROL SUBJECTS}

Patients contributing saliva for these studies were followed in the Cleveland Cystic Fibrosis Center. They ranged in age from 6 to 20 years. The degree of pulmonary disease ranged from severe to minimal as indicated by clinical scores (3) which varied from 37 to 91 . Normal control subjects ranged from 5 to 18 years of age. Two of the control donors of mixed saliva were hospitalized for nonpulmonary problems: neither was acutely ill or receiving drug therapy. Assays of submucosal and submandibular, but not sublingual and parotid secretions from one CF patient are reported here because the latter two secretions were collected only after the patient was started on prednisone therapy.

\section{SALIVA COLLECTIONS}

Each subject chewed chewing gum for $3 \mathrm{~min}$ before collection of mixed saliva. The gum was removed, the donor swallowed several times during the next $3 \mathrm{~min}$, and the saliva was collected in a plastic bottle for approximately $5 \mathrm{~min}$. Secretions were also collected for $10-30 \mathrm{~min}$ from sublingual and submandibular glands with Schneyer-type segregators (13) and from parotid and submucosal glands with Lashley cups (6). Secretion of saliva by the individual glands was stimulated by periodically dropping lemon juice on the posterior surface of the tongue. 


\section{PREPARATION OF SAMPLES}

Because Mangos reported that activity is lost when saliva is stored in glass (11), only plastic equipment was used in this study. Samples were diluted $1: 4$ by adding 1 volume of a solution containing $270 \mathrm{mM} \mathrm{NaCl}$ and 2 volumes of $0.9 \%$ $\mathrm{NaCl}$, giving a final sodium concentration of 135-145 $\mathrm{mEq} /$ liter. Particulate matter was then removed by centrifugation of the diluted saliva (15) and the supernatant was drawn into a plastic tuberculin syringe. Care was taken to expel all air bubbles. Samples were stored at $4^{\circ}$ and used within $4 \mathrm{hr}$.

\section{PREPARATION OF RATS AND RETROGRADE PERFUSION}

Sprague-Dawley rats (16) weighing 150-225 g were anesthetized by intraperitoneal injection of sodium pentobarbital, 6-7 $\mathrm{mg} / 100 \mathrm{~g}$ body weight. A tracheostomy was performed to insure adequate ventilation. A femoral vein was then cannulated with PE 10 polyethylene tubing for intravenous injection of pilocarpine. Both parotid gland ducts were cannulated with fine polyethylene tubing of approximately equal diameter (17). A length of this tubing $(3-4 \mathrm{~cm})$ was inserted in the left gland duct for the collection of control saliva samples and a $10-\mathrm{cm}$ length of this tubing, connected to a syringe containing the diluted saliva, was inserted in the right parotid duct. The right gland was partially exposed and the incision filled with mineral oil so that the gland could be observed under a dissecting microscope ( $X$ 50) during the retrograde perfusion. During the first $20-30 \mathrm{sec}$ of retrograde perfusion $0.04-0.05 \mathrm{ml}$ of sample was injected; thereafter, measured amounts were injected at a slower rate until the individual acini were seen to enlarge and separate. At this point constant pressure was maintained on the syringe plunger until $90 \mathrm{sec}$ inad elapsed after the start of the retrograde perfusion. The tubing was then cut $3-4 \mathrm{~cm}$ from the incision and pilocarpine was injected immediately into the femoral vein to stimulate salivary secretion by the rat. The saliva produced during the first $2 \mathrm{~min}$ was discarded. If the initial volumes excreted by the glands differed substantially, the slower and probably obstructed cannula was replaced quickly. Thereafter 8-10 timed serial collections were obtained from both glands over a $20-30-$ min period. The saliva was collected under oil in microcentrifuge tubes (18). The volumes of saliva secreted by the parotid glands of the rat were obtained by weight differences of the collection tubes, assuming that $1 \mathrm{mg}=1 \mu \mathrm{l}$. The body temperature of the rat was kept at $37-38^{\circ}$ throughout the entire procedure. This was accomplished by placing the rat on a temperature-controlled operating table (19) and monitoring the body temperature with a telethermometer and rectal probe (20). At the end of the experiment the rat was killed and the perfused gland resected to determine wet and dry weights. The dry weights were obtained after placing the glands in a $95^{\circ}$ oven for $18 \mathrm{hr}$.

\section{ANALYTICAL METHODS}

The sodium concentration of the rat parotid saliva was determined by flame photometry (21). Protein content of the perfused salivas was determined by the method of Lowry (7) using a bovine serum albumin standard.

\section{CALCULATIONS}

The rate of sodium reabsorption, $\left(\mathrm{R}_{\mathrm{Na}}\right)$, was calculated as described by Mangos et al. (12) for each timed saliva specimen. The average $R_{\mathrm{Na}}$ for each gland was obtained from values at comparable flow rates between 30 and $80 \mu 1 / \mathrm{min} / \mathrm{g}$ wet gland tissue. The percentage of inhibition of $R_{N a}$ was calculated using the formula: \% inhibition $=100-\{100 \times$ [(average $\mathrm{R}_{\mathrm{N} \text { a }}$ perfused gland)/(average $\mathrm{R}_{\mathrm{Na}}$ control gland)] \} .

\section{RESULTS}

Mixed saliva samples from $12 \mathrm{CF}$ patients and 12 normal control subjects were perfused in retrograde fashion into rat parotid glands. Twelve rats were also perfused with physiologic saline. Stimulated secretions from the different salivary glands of 9 CF patients and 9 control subjects were similarly perfused into rat parotid glands.

As shown by the data from a typical experiment (Fig. 1), the greatest difference between sodium concentrations of secretions from perfused and control glands was seen at flow rates below $80 \mu \mathrm{l} / \mathrm{min} / \mathrm{g}$ gland tissue. Above $80 \mu \mathrm{l} / \mathrm{min} / \mathrm{g}$ small errors in measurement of sodium concentration of rat parotid saliva result in unacceptably large errors of calcualted $R_{\mathrm{Na}}$. At flow rates below $30 \mu \mathrm{l} / \mathrm{min} / \mathrm{g}$ gland tissue, water is reabsorbed in the gland ducts (12), which results in lower calculated $R_{\mathrm{Na}}$ values. Therefore, the average $R_{\mathrm{Na}}$ values for each gland were obtained only from values at flow rates between 30 and $80 \mu \mathrm{l} / \mathrm{min} / \mathrm{g}$ tissue.

The volumes of diluted saliva injected into the rat parotid glands were found to be critical. The greatest inhibitory effect of $\mathrm{CF}$ mixed saliva occurred when the ratio of milliliters perfused per gram dry weight of the gland exceeded 1.8 (Fig. 2). Similar results were obtained with sublingual, submucosal, and submandibular secretions. If the ratio was higher than 2.8 , the rat parotid salivary flow rates were greatly reduced, usually to such an extent that there was no overlap of the flow rates of the two glands. Therefore, all the results reported in this paper are derived from experiments in which the ratios fall into the $1.8-2.8$ range.

In most of the experiments the flow rates of the perfused glands were lower than those of the control glands. In glands perfused with physiologic saline the average reduction of flow rate was $10 \%$. The flow rates of the glands perfused with normal and CF mixed saliva were reduced 16 and $23 \%$; with sublingual saliva, 12 and $23 \%$; with submandibular, 20 and $26 \%$; with submucosal, 27 and $27 \%$; and with parotid saliva, 15 and $11 \%$, respectively.

The percentage of inhibition of $R_{N \text { a }}$ reported in Table 1 shows that CF mixed saliva caused greater inhibition of $R_{\mathrm{Na}}$ than either normal mixed saliva or $0.9 \% \mathrm{NaCl}(P<0.01)$. The difference between $\mathrm{CF}$ and control submandibular or sublingual secretions was also highly significant $(P<0.01)$. The difference between the submucosal gland secretions of the two groups was also significant $(P<0.05)$, although less so. There was no difference between the inhibition of $R_{N}$ produced by

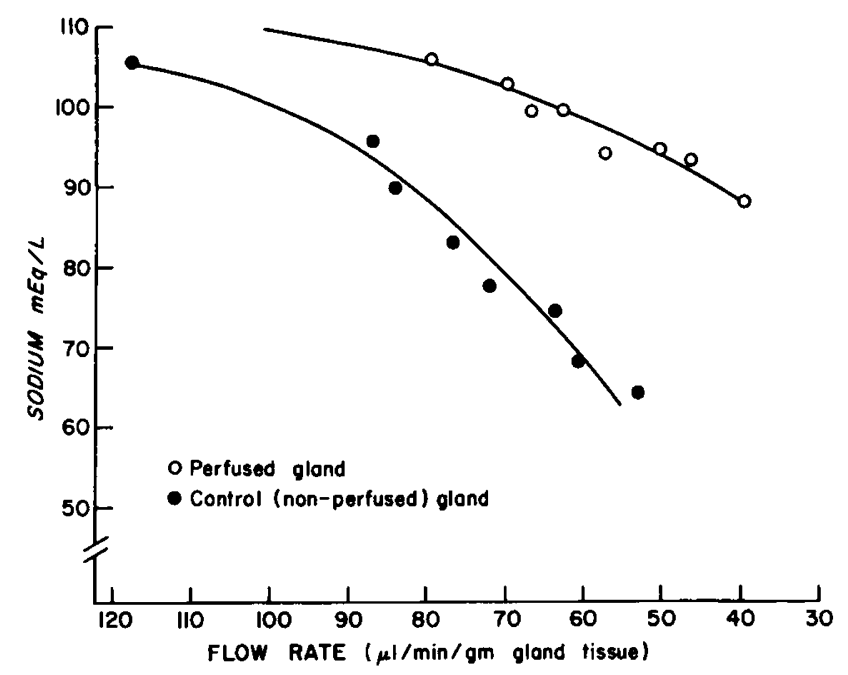

Fig. 1. Data from a typical experiment showing sodium concentration of rat parotid saliva plotted against salivary flow rate. One gland was perfused in retrograde fashion with cystic fibrosis submandibular saliva causing $39 \%$ inhibition of sodium reabsorption. 


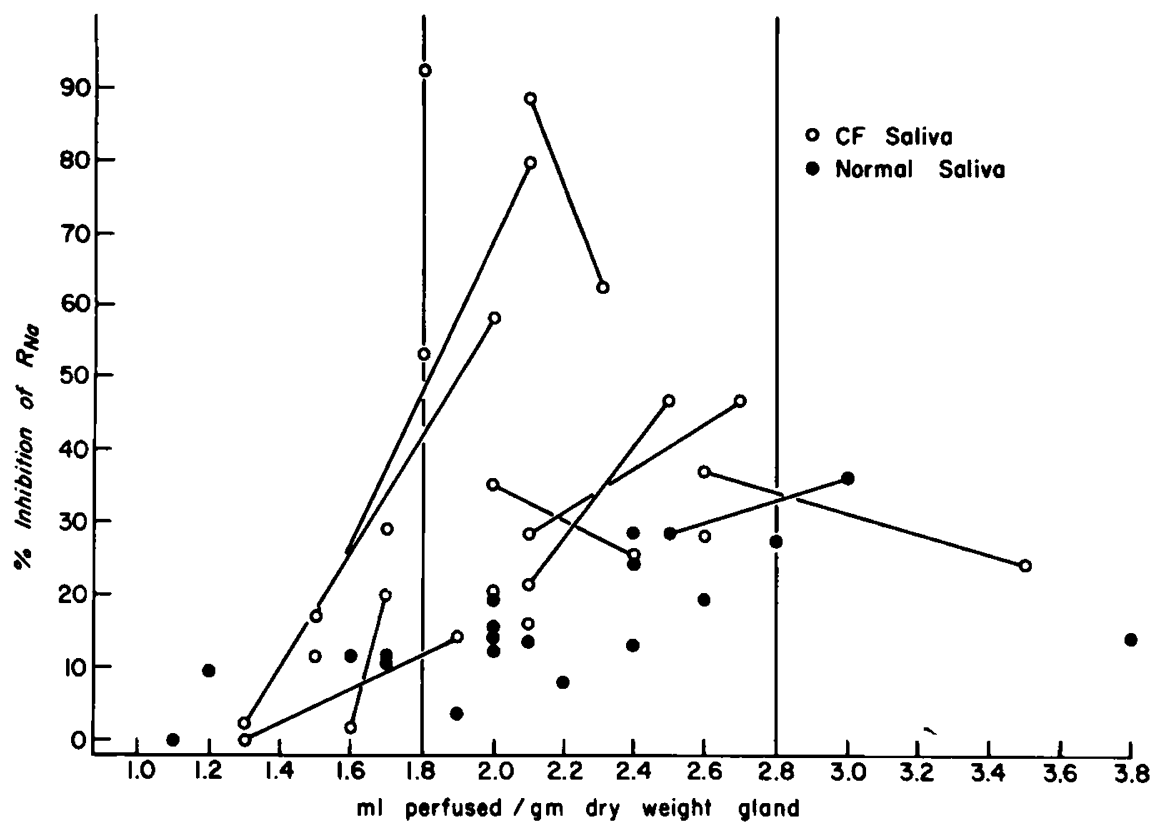

Fig. 2. Percentage of inhibition of $\mathrm{R}_{\mathrm{Na}}$ in rat parotid glands perfused in retrograde fashion with cystic fibrosis (CF) or normal mixed saliva plotted against the ratio of milliliters perfused per gram dry gland weight. Lines connect duplicate assays.

Table 1. Percentage of inhibition of rate of sodium reabsorption in rat parotid glands perfused in retrograde fashion with saline or salivary secretions 1

\begin{tabular}{lccc}
\hline & No. donors & $\begin{array}{c}\text { Inhibition } \\
\text { of } \mathrm{R}_{\mathrm{Na}}, \%\end{array}$ & $P$ value $^{2}$ \\
\hline $\mathrm{NaCl}$ & 12 & $12.7 \pm 7.4^{3}$ & \\
Mixed saliva & 12 & $18.0 \pm 8.3$ & \\
$\mathrm{~N}$ & 12 & $47.0 \pm 24.8$ & $<0.01$ \\
$\mathrm{CF}$ & & & \\
Sublingual saliva & 9 & $19.7 \pm 14.3$ & \\
$\mathrm{~N}$ & 8 & $39.5 \pm 6.0$ & $<0.01$ \\
$\mathrm{CF}$ & & & \\
Submandibular saliva & 9 & $16.0 \pm 11.8$ & \\
$\mathrm{~N}$ & 9 & $36.7 \pm 13.5$ & $<0.01$ \\
$\mathrm{CF}$ & & & \\
Submucosal saliva & 10 & $21.7 \pm 12.7$ & $<0.05$ \\
$\mathrm{~N}$ & 9 & $34.0 \pm 11.7$ & \\
$\mathrm{CF}$ & & & \\
Parotid saliva & 9 & $12.5 \pm 6.6$ & $<\mathrm{NS}$ \\
$\mathrm{N}$ & 8 & $12.5 \pm 7.9$ & \\
$\mathrm{CF}$ & & &
\end{tabular}

${ }^{1} \mathrm{CF}$ : cystic fibrosis; $\mathrm{N}$ : normal.

${ }^{2}$ Student $t$ test.

${ }^{3} \mathrm{SD}$.

the parotid secretions of CF and control salivas. In addition, parotid secretions, stimulated by sour candy rather than by lemon juice, from eight $\mathbf{C F}$ and two normal donors yielded mean values of 5.1 and 10.1 , respectively, for percentage of inhibition of $R_{\mathrm{Na}}$. All of the control salivas caused minimal inhibition, as did saline.

The results of saliva samples that were assayed twice for inhibition of $R_{\mathrm{Na}}$ using two different rats, are reported in Table 2. The average difference between the duplicate assays was $12.2 \%$.

To test the validity of the assay procedure sublingual secretion samples obtained from six CF and five normal donors were assayed by one of us $(A T)$ without knowledge of the source. The average percentage of inhibition of $\mathrm{R}_{\mathrm{Na}}$ by the
Table 2. Percentage of inhibition of $R_{N a}$ by salivary secretions that were assayed twice using two different rats ${ }^{1}$

\begin{tabular}{lc}
\hline Saliva sample & Inhibition, \% \\
\hline CF mixed & 25.7 \\
& 35.1 \\
CF mixed & 28.8 \\
CF mixed & 46.9 \\
& 88.0 \\
CF mixed & 62.9 \\
CF submucosal & 47.0 \\
& 21.6 \\
CF parotid & 17.4 \\
& 31.6 \\
CF sublingual (18) & 0 \\
& 2 \\
CF sublingual (18) & 75.3 \\
& 73.4 \\
CF sublingual (18) & 77.0 \\
& 30.5 \\
Normal mixed & 35.6 \\
& 44.7 \\
Normal mixed & 58.2 \\
& 15.9 \\
Normal parotid & 14.9 \\
Normal parotid & 25.7 \\
& 35.1 \\
& 30.7 \\
& 20.6 \\
& 20.9 \\
& 0 \\
\hline
\end{tabular}

'CF: cystic fibrosis.

CF secretions was $43.7 \pm 25.2 \%$ (mean \pm SD) and by the normal secretions was $16.8 \pm 9.8 \%$ with a $P$ value of $<0.05$. These results are similar to those obtained with the sublingual secretions reported in Table 1.

Studies were done to determine whether there was a correlation between protein concentration of the perfused saliva and the degree of inhibition of $R_{\mathrm{Na}}$. The average protein concentration in the CF mixed saliva was significantly higher 
than that in normal mixed saliva, $181 \pm 66$ and $106 \pm 39$ $\mathrm{mg} / 100 \mathrm{ml}$, respectively $(P<0.01)$; however, within each group there was no correlation $(r=-0.048$ and -0.396 , respectively) between the percentage of inhibition and the protein concentration (Fig. 3 ).

The degree of inhibition of $\mathrm{R}_{\mathrm{N}}$ displayed by 38 nonparotid CF saliva samples from 21 patients showed no correlation with the clinical scores of these patients $(r=-0.132)$.

\section{DISCUSSION}

This study confirms the earlier observation of Mangos (12) that CF mixed saliva causes inhibition of sodium reabsorption in the rat parotid gland ducts, and furthermore shows that this effect is also present in submandibular, sublingual, and submucosal, but not in parotid secretions.

The results with $\mathrm{CF}$ secretions from the four types of salivary glands suggest that an inhibitory factor is secreted by CF glands that contain mucous-type cells. Parotid glands which contain almost entirely serous cells produce saliva that has no inhibitory effect. Sublingual, submandibular, and submucosal glands, which in CF patients produce saliva that causes inhibition of sodium reabsorption, are made up of a combination of serous and mucous cells (1), with serous cells predominating in the submandibular glands, and mucous cells predominating in the sublingual and submucosal glands.

CF saliva generally has a higher protein concentration than normal saliva $(8,9)$, particularly submandibular saliva, and this was true for the saliva samples used in this study. However, no relation between total protein concentrations and inhibition of sodium reabsorption could be established. Further studies are needed to elucidate potential effects of alterations of specific protein components in $\mathrm{CF}$ saliva on sodium reabsorption.

There is no ready explanation for the greater inhibitory effect exhibited by CF mixed saliva than that exhibited by $\mathrm{CF}$ secretions of the different salivary glands. However, the individual secretions were collected at higher flow rates, induced by lemon juice stimulation, than the mixed saliva, which was stimulated by gum chewing.

It was difficult to determine the volume of diluted saliva necessary to cause inhibition by visual observation of the gland during the perfusion. By using the ratio of milliliters perfused per gram of dry gland weight we were able to determine the most effective range of ratios for inhibition of $R_{\mathrm{Na}}$. Since the ratios of the reported values fall within defined limits, the assays of both CF and normal salivas are uniform in regard to the volumes perfused.

When the salivary flow rates of the samples collected simultaneously from both glands were compared, the flow rates of the perfused glands were almost always reduced. Since the calculated percentage of inhibition of $R_{N a}$ was derived

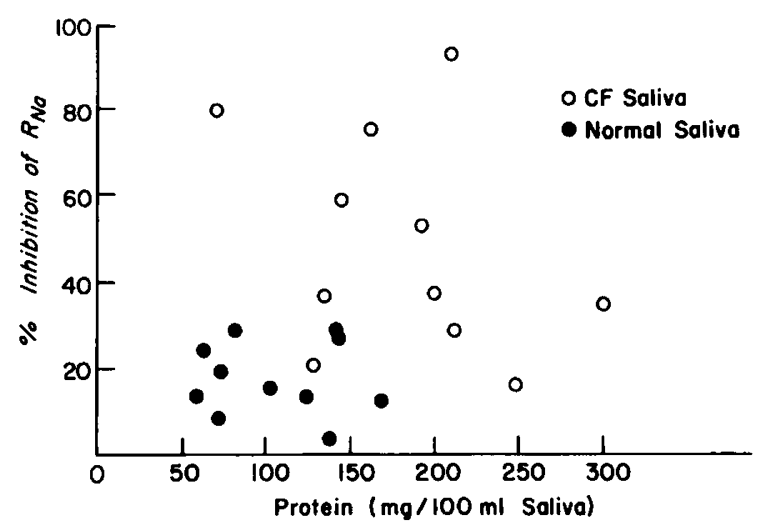

Fig. 3. Percentage of inhibition of $\mathrm{R}_{\mathrm{Na}}$ in rat parotid glands perfused in retrograde fashion with cystic fibrosis (CF) or normal mixed saliva plotted against protein concentration of the test saliva samples. from samples with similar flow rates and not necessarily from samples collected at the same time intervals after pilocarpine stimulation, it was thought that the differences in the time of collection after stimulation of perfused and control glands might be a factor leading to the observed differences of the percentage of inhibition of $R_{\mathrm{Na}}$. However, when we expressed the percentage of inhibition of $R_{N a}$ as a function of time after pilocarpine stimulation, we found that the percentage inhibition of $R_{\mathrm{Na}}$ was not appreciably different from that obtained by comparing the $R_{\mathrm{Na}}$ values of the two glands at similar flow rates.

Mangos used a different group of rats for his nonperfused controls and reported his results as the rate of sodium reabsorption. When the percentage of inhibition of $\mathrm{R}_{\mathrm{Na}}$ is calculated from average values in his data, the glands perfused with CF saliva showed $68 \%$ inhibition of $\mathrm{R}_{\mathrm{Na}}$ compared to the nonperfused group, which is higher than in our study. This difference may be at least in part due to the fact that we used the nonperfused gland of each rat as the control in every experiment and calculated the percentage inhibition of $R_{\mathrm{Na}}$ for each rat before obtaining a mean value. In our experiments the $\mathrm{R}_{\mathrm{Na}}$ values of the control glands varied from $2-8 \mu \mathrm{Eq} \mathrm{Na}$ reabsorbed $/ \mathrm{min} / \mathrm{g}$ tissue. However, the percentage of inhibition of $\mathrm{R}_{\mathrm{Na}}$ was consistent when saliva samples were perfused in two different rats.

Although the differences between the percentage of inhibition of the CF and normal secretions were statistically significant, we found a substantial overlap of these values for saliva collected from all sources as well as some variation in the values of samples collected on different days from some of the same patients. Therefore, we cannot recommend that this procedure be used as a diagnostic test for CF. Instead, it is hoped that standardization of the assay methodology and identification of those salivary secretions causing the inhibitory effect will lead to isolation and characterization of the inhibitory substance or substances, and ultimately to clearer understanding of the pathogenesis of cystic fibrosis.

\section{SUMMARY}

These studies confirm previous findings of a sodium reabsorption inhibitory effect in mixed saliva from $\mathrm{CF}$ patients by using a modification of the original retrograde perfusion technique of Mangos and, furthermore, show the effect to be present in sublingual, submandibular, and submucosal secretions but not in the parotid secretions of CF patients. This effect appears to be found only in secretions from those salivary glands which contain a significant number of mucous-type cells, indicating that mucous cells play a role in its production. These modifications of the methodology should facilitate isolation and characterization of the substance or substances that cause inhibition of sodium reabsorption.

\section{REFERENCES AND NOTES}

1. Bloom, W., and Fawcett, D. W.: A Textbook of Histology, Ed. 9, p. 521-22 (W. B. Saunders Co., Philadelphia, Pa., 1968).

2. Di Sant'Agnese, P. A., Darling, R. C., Perera, G. A., and Shea, E.: Abnormal electrocyte composition of sweat in cystic fibrosis of pancreas: Clinical significance and relationship to disease. Pediatrics, 12: 549 (1953).

3. Doershuk, C. F., Matthews, L. W., Tucker, A. S., Nudelman, H., Eddy, G., Wise, M., and Spector, S.: A five year clinical evaluation of a therapeutic program for patients with cystic fibrosis. J. Pediat., 64: 677 (1964).

4 Johansen, P. G., Anderson, C. M., and Hadorn, B.: Cystic fibrosis of the pancreas: A generalized disturbance of water and electroly te movement in exocrine tissues. Lancet, $1: 455$ (1968).

5. Kaiser, D., Drack, E., and Rossi, E: Inhibition of net sodium transport in single sweat glands of patients with cystic fibrosis of the pancreas. Pediat. Res., 5: 167 (1971).

6. Lashley, K. S.: The human salivary reflex and its use in psychology. Psychol, Rev., 23: 466 (1916).

7. Lowry, O. H., Rosebrough, N. J., Farr, A. L., and Randall, R. J.: 
Protein measurement with the Folin phenol reagent. J. Biol. Chem., 193: 265 (1951).

8. Mandel, I. D., Kutcher, A., Denning, C. R., Thompson, R. H., and Zegarelli, E. V.: Salivary studies in cystic fibrosis. Amer. J. Dis. Child., 113: 431 (1967).

9. Mandel, I. D., Thompson, R. H., Wotman, S., Taubman, H., Kutcher, A. H., Zegarelli, E. V., Denning, C. R., Botwick, J. T., and Fahn, B. S.: Parotid saliva in cystic fibrosis. Amer. J. Dis. Child., 110: 646 (1965).

10. Mangos, J. A., and McSherry, N. R.: Sodium transport: Inhibitory factor in sweat of patients with cystic fibrosis. Science, 158: 135 (1967).

11. Mangos, J. A., and McSherry, N. R.: Studies on the mechanism of inhibition of sodium transport in cystic fibrosis of the pancreas. Pediat. Res., 2: 378 (1968).

12. Mangos, J. A., McSherry, N. R., and Benke, P. J.: A sodium transport inhibitory factor in the saliva of patients with cystic fibrosis of the pancreas. Pediat. Res., 1: 436 (1967).

13. Schneyer, L. H.: Collection of separate submaxillary and sublingual salivas in man. J. Dent. Res., 33: 683 (1954).

14. Weisman, U. N., Boat, T. F., and Di Sant'Agnese, P. A.: Elevated sodium chloride in saliva. Lancet, $i$ : $510(1972)$.

15. Samples were centrifuged for 5 sec at $15,000 \mathrm{rpm}$ in a Beckman microf uge, model 152 .
16. Obtained from Sprague-Dawley, Madison, Wisc.

17. Made by heating polyethylene tubing (Clay Adams PE 100) and drawing it out to the desired diameter.

18. Beckman no. 314326, Beckman Instruments, Palo Alto, Calif.

19. A standard heated rat operating table built at the University of Wisconsin machine shop was used.

20. Yellow Springs Instrument Co, Yellow Springs, Ohio. Telethermometer, model no. 41TA, and internal probe no. 401 .

21. Flame photometer model 143, Instrumentation Laboratory, Inc., Lexington, Mass.

22. The sublingual salivas reported in this table were stored at $-20^{\circ}$ for 10 days or less before they were used; therefore they are not included in the data in Table 1.

23. Informed consent was obtained for all subjects in this study.

24. The authors wish to thank Dr. John A. Mangos and Mrs. Nona R. McSherry for their helpful suggestions and assistance.

25. This work was supported by the United States Public Health Service Grant no. AM-08305; the Cystic Fibrosis Foundation, Cleveland Chapter, via the Health Fund of Cleveland.

26. Requests for reprints should be addressed to: L. W. Matthews, M.D., Department of Pediatrics, Case Western Reserve University, Cleveland, Ohio 44106 (USA).

27. Accepted for publication June 24, 1974.
Arylsulfatase A genetic disorder I-cell disease

\title{
Studies on the Pathogenetic Mechanism of I-Cell Disease in Cultured Fibroblasts
}

\author{
U. N. WIESMANN ${ }^{(26)}$ AND N. N. HERSCHKOWITZ
}

Department of Pediatrics, Divisions of Cellbiology and Neurochemistry, University of Berne, Berne, Switzerland

\section{Extract}

A marked intracellular reduction of six lysosomal enzymes could be demonstrated in fibroblasts from four different patients with mucolipidosis type II or I-cell disease. In contrast to that finding, conditioned media from the same cells contained a $2-10$-fold increase of the activities of five lysosomal enzymes over control values. In obligate heterozygotes elevated lysosomal enzyme activities in the conditioned media were also found, but normal enzyme activities were measured intracellularly. A functional impairment of the lysosomal degradation of $\left({ }^{35} \mathrm{SO}_{4}\right)$ mucopolysaccharide (MPS) and of $\left({ }^{35}\right.$ S)-sulfatide could be shown in the I-cell fibroblasts, as a consequence of decreased enzyme activities.

Substitution of the enzyme-deficient cells with normal urinary arylsulfatase $A$ and with mucopolysaccharide degrading factors from normal conditioned media was possible, but failed when urine from patients or conditioned media factors from the I-cell fibroblasts were used.

\section{Speculation}

Genetic disorders of lysosomal functions can be caused not only by lack of synthesis or by a structural defect of a lysosomal enzyme, but also by a genetically determined loss of enzyme into the extracellular fluid. These lysosomal enzymes are functionally abnormal only insofar as they cannot be retained within the cells, and, furthermore, once they are outside of the cells, they can not re-enter the cells by pinocy tosis as can normal enzymes.

Mucolipidosis II or inclusion cell (I-cell) disease is an inherited condition clinically resembling a classic mucopolysaccharidosis, without the typical excessive excretion of mucopolysaccharides in urine (15). Highly increased levels of lysosomal enzyme activities are found in the extracellular fluids of the patients $(17,21,22)$. In cultured fibroblasts from patients typical granular cytoplasmic inclusions are seen, hence, the name I-cell disease (10). A multiple deficiency of lysosomal enzymes has been demonstrated in cultured I-cell fibroblasts $(10,11)$. In a preliminary report (18) we have shown that increased lysosomal enzyme activities also can be measured in conditioned culture medium of I-cell fibroblasts. We have now confirmed these findings for a number of different I-cell lines from patients with mucolipidosis II and have studied the impact of the multiple enzyme deficiency on lysosomal function in the I-cell fibroblasts. Furthermore, the 